\title{
Increasing Diversity via Augmented and Distributed Online Conferences
}

\author{
Alejandrina Cristia \\ Laboratoire de Sciences Cognitives et de Psycholinguistique, \\ Département d'études cognitives, ENS, EHESS, CNRS, PSL University \\ 29 rue d'Ulm, 75005, Paris, France \\ alecristia@gmail.com
}

\begin{abstract}
Language and speech technologies can become available 'for all' only if we increase access to knowledge and networking opportunities, particularly for scientists who are geographically distant from Europe and North America, and who likely have a limited travel budget. I propose a relatively cheap and scalable strategy to do so: The creation of augmented and distributed online conferences. Participants travel to a central areal location to view the streamed conference together, and online (video-)chats allows such virtual attendees to interact with physical conference attendees. Benefits include the promotion of areal networks, increased learning through active participation, and reduced environmental costs.
\end{abstract}

Keywords: knowledge dissemination, diversity, networking, environmental impact

\section{Résumé}

Las tecnologías de lenguaje y habla pueden estar disponibles 'para todos' solo si aumentamos el acceso al conocimiento y las oportunidades de establecer contactos, particularmente para los científicos que están geográficamente distantes de Europa y América del Norte, y que probablemente tienen un presupuesto de viaje limitado. Propongo una estrategia relativamente barata y escalable para hacerlo: la creación de conferencias en línea distribuidas y aumentadas. Los participantes viajan a una ubicación central para ver la conferencia transmitida juntos, y (video-)chats en línea permiten que dichos asistentes virtuales interactúen con los asistentes físicos a la conferencia. Los beneficios incluyen la promoción de redes de área, mayor aprendizaje a través de la participación activa y costos ambientales reducidos.

\section{Motivation}

In speech and language technology, a primary mode of knowledge creation and dissemination are conferences. In this paper, I will set aside the issue of whether and why paper evaluation should be tied together with a physical presentation. Instead, I will focus on short-comings of current conference organization in terms of geographic and linguistic biases, and some related problems.

First, access to conferences is easier for scientists who are located close to where conferences because of lower time and moneyf travel costs. By and large, this advantages scientists in the Northern Hemisphere, and typically those residing in North America and Europe, thus disadvantaging researchers from low- and- middle-income (LMIC) countries and even scientists living in relatively wealthy countries but with no travel budget. Sometimes, researchers attempt to counter this bias by convening conferences in other locations. When doing so, however, they worsen the second issue, as follows.

Second, physical conferences imply a steep cost to the environment. In a recent study of six conferences from the European Consortium for Political Research (which thus was attended primarily by attendees from the same continent), (Jäckle, 2019) estimated each visitor caused .5-1.3 tons of $\mathrm{CO}_{2}$ equivalents per conference when they happened in $\mathrm{Eu}-$ rope, and 1.9-3.4 tons for one held in Montreal.

Third, even in cases where scientists from LMIC can access conferences, they likely benefit less. To begin with, very often conferences are conducted in a major language which may not be those scientists' native tongue, meaning they may learn less when viewing presentations because they cannot adjust the rhythm or speed of the presentation.
Moreover, question periods may happen too quickly for someone who may need a moment to find their words when speaking. As a result, such attendees may get used to the idea of not asking questions, becoming passive listeners. In addition to this having a negative impact in their informational uptake (Jensen et al., 2015), this deprives them from an opportunity to display themselves and attract colleagues' attention.

This connects with a fourth issue that is likely to result in decreased diversity in academia, which is inequality in access to networking opportunities, for which conferences appear irreplaceable. Giving a presentation or even asking a question that others shared is an excellent conversation starter, as these other audience members may come up to the presenter or question asker to continue the conversation. Coffee breaks and other open discussion periods are often prized moments to approach researchers with whom we have a passing acquaintance that we want to reinforce, or even people we would like to introduce ourselves to. However, even if scientists from LMIC attend conferences, these times may be yet another stressful opportunity, when one is forced to socialize orally in a non-native language now in the presence of background noise high enough to make even native speakers find the experience tiresome. Over time, attempting to follow presentations and discussions in a non-native language causes fatigue, which compounds all of the aforementioned negative effects.

\subsection{Current alternatives}

In the scientific world, there have been repeated calls to move towards online conferences, primarily in order to minimize their environmental impact. For example, a re- 
cent proposal has been made for "nearly carbon-neutral conferences", based on several successful attempts (Ken Hiltner, 2017), and which assumes that physical presence may no longer be required even for presenters because they can send in video-recordings of their presentations, and discussion can occur in the form of comments to blog entries. Some readers may find such an idea threatening, requiring a whole re-thinking of the place of conferences in today's professional world. Additionally, it is unclear whether the same level of engagement and comprehension can be obtained when there is no real-time interaction. A hybrid alternative has been proposed (Fraser et al., 2017), according to which we could organize conferences in multiple locations at the same time. This is certainly a promising direction, and could eventually replace fully centralized physical conferences.

Twitter users may feel that there is already a possibility for people not attending a conference to follow it, provided someone is live tweeting the event. Others have already pointed out some limitations of this, including most saliently that the short format required by twitter virtually enforces simplification (Erin Zimmerman, July 30 2019). In addition, this system is mainly for individuals who are physically present to broadcast what they choose to discuss, with limited opportunities for researchers in LMIC to impact the discussion. Additionally, there is no structure supporting networking for these peripheral participants.

Several of the problems summarized above relate to processing and producing non-native speech. In the industrial world, there are current solutions for the question of language mismatches between attendee and speaker. For instance, Interactio provides online translation services that are streamed directly to audience members' smartphones (?)interactio). I think it is unlikely such a solution will work for science because of its economic cost and the difficulty of finding translators who can follow and accurately translate scientific presentations.

\section{Augmented and Distributed Online Conferences (ADOC)}

The main idea is to augment the current system of physical, centralized conferences using online resources and geographic distribution. I will discuss three use cases, the first being when there is a conference that has online streaming; the second a conference with no online streaming; and the third for a conference being organized from scratch.

\subsection{Augmenting a conference that has online streaming}

Let us assume there exists a conference whose conveners have decided to live stream. Even without discussion with and agreement by the conveners, the audience can selforganize to increase the chances that potential audience members who cannot attend physically nonetheless benefit from the content presented, live discussions, and some networking opportunities.

The first component of an ADOC is its augmentation, and I propose it can currently rest on private but free platforms: Slack, Google products (Forms, Hangouts), and Youtube.
A Slack workspace should be created with the following features:

- An Announcements channel, where key information is posted (including descriptions of all channels, and instructions for creating new channels)

- A channel for each session, so that (e-)attendees to that session can post questions/comments on it

- A bio channel, where groups and/or individuals can post some information about themselves, including keywords representing their research interest

This workspace should be widely advertised and a google form should be created. This form serves to collect email addresses necessary to invite respondents to the Slack workspace. In addition, the form asks them to specify whether they'll be attending the event physically or online. In the former case, respondents are asked whether they are open to being the question askers for online participants for a given session (and if so, which). Respondents are also asked whether they volunteer to help with the organization of the ADOC. Respondents who participate online and agree to volunteer can help manage the Slack workspace (adding participants, trouble-shooting, moderating channels when needed).

The second component of a ADOC is its distributed nature, whereby events that coinicide in time with the actual conference are organized in geographically distributed locations. Let us imagine that three people in Senegal would like to e-attend an event in Paris. They would book a room in one of their universities, which has a good bandwidth and online conferencing equipment (a camera, a microphone, a large screen). They would also look into opportunities to have food delivered, or instead decide to skip connecting with the Parisian event during lunch breaks. They would either agree to all watch the same event on the large screen, with an opportunity to discuss it; or instead decide to watch different events, and recap the results for each other. Let us imagine that a group of seven people in Mali will be doing the same.

As these online attendees follow the conference, they may ask questions on the Slack channel dedicated to each session. Other physical or online attendees may choose to answer the question, or +1 the question to indicate they would like for it to be asked in the question period. When question period comes, physical attendees who agreed to be question askers would ask the most up-voted question.

Throughout the conference, online and physical attendees can also create new channels to continue targeted discussions. Imagine someone asks a question about the precise structure of an RNN to be used in a diarization task, which he/she knows interests two other people. They can create a channel called "RNN-dia" a google hangouts room and advertise this in the Announcements channel. After the conference is over, a longer term collaboration could emerge between these eight people if they continue the discussion within the Slack workspace, through contact information shared that day, or present in their bios (in the bio channel). In addition, Slack has a system for direct messaging. Although not the same as standing in line to introduce oneself 
to someone famous, this would allow e-attendees a chance to connect with these people (provided both sign up to the e-conference).

\subsection{Augmenting a conference that does not have online streaming}

This case is almost exactly as the above, except that the physical volunteers become crucial because not only will they ask questions in the question period, but they should also video- or at least audio-stream the conference for the people who are e-attending. To this end, they must create an account on Youtube, and learn how to live stream to a private channel. It must be to a private channel because attendees to the conference did not sign a release for their image and speech to be shared publicly with no restraint. In addition to this change, the Google Form in which people sign up to attend the e-conference must include an ethics section explaining that it is not allowed to share the Youtube channel link with third parties, or to reproduce the content elsewhere.

\subsection{Creating a conference from scratch}

For readers who are creating a conference from scratch, they could borrow ideas from (Ken Hiltner, 2017) for a fully virtual conference, and (Fraser et al., 2017) for a number of other options combining virtual presence with regional contact. Organizers may prefer to still hold a traditional conference in a single site. In this case, they could simply contemplate charging a small fee to online participants to cover costs for the paid versions of Slack, and Youtube livestreaming.

Also, it would be ideal for the organizers to make sure that there is appropriate space, time, and bandwidth so that physical attendees can interact with the e-attendees during coffee breaks and poster sessions. For instance, there could be alcoves or other smaller spaces ideal to have Google hangout discussions using one's phone.

\section{Comparison between DACO and conferences as usual}

\subsection{Expected relative benefits}

Numerous relative benefits are expected. To begin with, being with others (in the distributed setting) or at least connected online with physical attendees means that online attendees would benefit from a more active experience, so they may learn better during the talks. In addition, nonnative listeners who meet up with others in the distributed setting may be able to discuss and translate into their native language, further improving understanding.

Questions in the question period would represent people who are not physically in the audience. This benefits not only e-attendees, whose voice may now be heard, but also presenters, who can benefit from a wider diversity of perspectives on their work. Indeed, I suspect that the discussions in the session-specific channels will be beneficial to both e- and physical attendees.

E-attendees would benefit from increased chances to network with others present in the conference, a possibility that is completely absent in the current system. In fact, it is often difficult to connect with others having similar interests in large conferences, simply because there are too many people and there is typically nothing in their physical appearance that allows us to know we share an interest. Moving some of these issues to the virtual world may further facilitate discussion with others even for physical participants.

In today's conferences, fascinating discussions that one strikes in the coffee break are quickly forgotten as one speeds to the next talk. By creating a structured space to carry on targeted conversations, ADOCs allow a physical trace of some of these conversations, and may even provide a natural setting for these ephemeral chats to flourish into collaborations.

There are additionally two benefits that are not related to allowing participation from geographically and linguistically diverse audiences. First and foremost, ADOCs would allow some to optionally not attend physically, resulting in reduced environmental impact of the conference. Additionally, they may increase diversity in other ways, being a good option for primary caregivers who cannot physically travel far or for an extended period of time; they may provide unique interaction opportunities to people who are shy or suffer from social anxiety; and they also benefit students and junior researchers, who typically do not have a travel budget and cannot afford physical participation to conferences.

\subsection{Expected relative costs}

The main cost is time: to organize the workspaces, write instructions, publicize, process incoming information, train volunteers. This should be measured, and could be compared against the time savings of reduced travel.

In addition, there may be some security risks. Particularly in conferences that do not have a live-streaming component, some may feel challenged about having their talks live-streamed to a private Youtube channel. In general, today's attendees may operate under the assumption that presentations and comments are done in a closed room and will be quickly forgotten. Thus, a shift in how speakers present may be required.

\subsection{Measurement of effects}

While writing this paper, I realized that although there are many discussions regarding the role of conferences, their importance for career development, their negative environmental effects, there seem to be relatively few actual quantitative studies teasing apart correlation from causation, and opinion from fact (e.g., (Prpić, 2000; Rowe, 2018)). Work on actually proposing alternatives and measuring relative impact is, to my knowledge, non-existent.

It is crucial to actually calculate the benefits and costs of different types of conferences or conference features from now on. Often the opening talk at a conference comments on diversity in terms of the proportion of people coming from different sites, which seems a good place to start, but an insufficient metric.

We could measure comprehension of talks by asking speakers to use online polls to check for content comprehension, providing different links to online versus physical atten- 
dees; the prediction is that e-attendees who participate in distributed groups understood the talk's contents better than those watching alone; and a key question is whether those two groups understood the talk's contents any differently from physical attendees.

Using names or other identifiers provided during registration could help direct network analyses. One prediction is that physical conference attendees and e-attendees are more likely to cite each other, or co-publish, after the conference than before; a control group can also be defined using a conference without $\mathrm{ADOC}$, to calculate the base rate of mutual citation. It is an open question whether physical attendees will cite each other more than they cite eattendees, and vice versa. We can also test the prediction is that post-doctoral researchers and students who eparticipate are more likely to be hired by e- or physical participants than a group of control students, or some established base rate, with follow-up hypotheses regarding the relative advantage of students/post-docs who attended physically versus online only.

Finally, one could check the prediction is that e-attendees will have much shorter travel times, even if they meet a geographically distributed group, and will contribute less $\mathrm{C} 02$ and other environmental costs. Another key question is whether e- and physical attendees end up attending a similar proportion of the talks.

\subsection{Limitations}

While ADOC may provide a solution to some of the problems current purely physical, centralized conferences pose, they do not fix all of them. In particular, this solution is not useful to scientists living in countries where the internet infrastructure is poor. Additionally, they represent only a partial solution for those who cannot book a wellequipped videoconferencing room in their university, and instead may need to log in from a home or a café. Additionally, some conference organizers may feel they are losing money in this way, and it is unfair for e-attendees to not pay any of the costs the conference conveners have engaged in.

Perhaps in the future conferences will be organized with these three limitations in mind. They could be addressed by organizing the conference as a distributed event from scratch, such that the fee depends on which site the attendee goes to. If attending from UK, the fee may be around $500 \$$ taking into account not only the costs of the central organization of the program but also the conference center, food delivery, and other costs local to the UK; but attendees to the Buenos Aires site may only pay $100 \$$ for the same services. This fee would thus pay for the local videoconference and food costs in an actual conference site, whereas some of it would go to the central conference conveners.

Even in this case, however, some issues remain unresolved. We still do not have a good solution for the fact that publication in major languages still benefits native speakers of those major languages, whereas publication in smaller languages currently has a much lower readership. Similarly, none of these solutions are perfect to balance the scale in terms of networking: Scientists from famous labs may still find it easier to meet people, find good collaborators, hire and be hired, than scientists in less prominent sites.

\subsection{LT4All as a use case}

The International Conference Language Technology for All provides an excellent use case for the ADOC proposal, falling neatly in the first use case mentioned above (a conference that is live streamed). I have set up a Slack workspace (1t4all2019.slack. com) and a Google Form (https://forms.gle/ yTT 8 8GR1 nWkWdNs 8A).

This paper is available as a preprint from https: / / os f . io/s 4 bta. In that version, I may be able to update the information on some of the metrics proposed above. Geographical origin of physical and e-attendees, as well as travel time, will be gathered via an anonymized Google Form, and can serve to estimate $\mathrm{C} 02$ and other environmental costs. If I find any speakers who are willing to use online polls to check for content comprehension, this could serve to answer whether distributed and/or online participation can be equivalent in terms of learned content.

\section{Conclusion}

In this paper, I have proposed the concept of Augmented and Distributed Online Conferences (ADOCs), as a way to increase the dissemination of scientific information that is available in conferences to scientists who may reside in geographically spread locations, with likely added benefits in terms of networking opportunities. Ultimately, the question of how useful ADOCs are is an empirical one, and I look forward to there being data to answer it.

\section{Acknowledgements}

I am grateful to the womenNspeech mailing list and Emmanuel Dupoux for helpful discussion. All errors are my own.

\section{References}

Erin Zimmerman. (July 30, 2019). Live tweeting science conferences: The good, the bad, and the ugly. last visited 2019-11-20.

Fraser, H., Soanes, K., Jones, S. A., Jones, C. S., and Malishev, M. (2017). The value of virtual conferencing for ecology and conservation. Conservation Biology, 31(3):540-546.

Jäckle, S. (2019). WE have to change! The carbon footprint of ECPR general conferences and ways to reduce it. European Political Science, 18:630-650.

Jensen, J. L., Kummer, T. A., and Godoy, P. D. d. M. (2015). Improvements from a flipped classroom may simply be the fruits of active learning. CBE-Life Sciences Education, 14(1):ar5.

Ken Hiltner. (2017). A nearly carbon-neutral conference model. last visited 2019-11-20.

Prpić, K. (2000). The publication productivity of young scientists: An empirical study. Scientometrics, 49(3):453-490.

Rowe, N. (2018). When you get what you want, but not what you need: The motivations, affordances and shortcomings of attending academic/scientific conferences. 
International Journal of Research in Education and Science, 4(2):714-729. 